\title{
CONTRAPUNTO: EL ABORTO TERAPÉUTICO
}

\section{OPOSSITE VIEWPOINT: THERAPEUTIC ABORTION}

\begin{abstract}
La Dirección de la Revista Chilena de Derecho invitó a participar en la sección Ensayos y Crónicas a los profesores de Derecho Penal Juan Pablo Hermosilla (en adelante JPH) de la Universidad Diego Portales y Alex van Weezel (en adelante AVW) de la Pontificia Universidad Católica de Chile, para que respondieran cuatro preguntas relativas al aborto terapéutico, donde se analiza desde su definición hasta su compatibilidad con la actual Carta Fundamental, todo en referencia a los actuales proyectos presentados para la modificación legislativa del tema en comento.
\end{abstract}

\section{Profesores Juan Pablo Hermosilla ${ }^{1}$ (JPH) y ALEX VAN WEEZEL (AVW) ${ }^{2}$}

\section{1) ¿QUÉ ENTIENDE USTED POR ABORTO TERAPÉUTICO?}

JPH: El aborto terapéutico denomina a situaciones en las cuales entra en conflicto la salud de la madre con la vida del feto, de forma tal que para proteger aquella se requiere lesionar la vida de este.

AVW: El sustantivo "aborto" tiene dos significados muy distintos: en la medicina, es la muerte incluso espontánea de la criatura en gestación y, por lo tanto, sin connotación valorativa. En cambio, en el derecho chileno el aborto es un delito que consiste en dar muerte a la criatura. Aunque tienen en común la muerte del que está por nacer, el significado es muy distinto.

Sin embargo, cuando se agrega el adjetivo "terapéutico", las diferencias anteriores tienden a pasar desapercibidas, y ese es el problema. La idea de "terapia" implica un procedimiento voluntariamente emprendido para obtener un fin curativo, de modo que en este caso se trataría de realizar un tratamiento curativo que provoca la muerte de la criatura. Luego, la expresión "aborto terapéutico" alude a dos realidades cuyo significado es totalmente diferente: Por un lado, puede significar "matar a la criatura como medio para lograr un buen fin (curativo)", pero también puede significar "realizar un procedimiento donde la muerte de la criatura no es el medio para curar, pero puede sobrevenir como consecuencia no deseada". En el primer caso, la decisión depende de una ponderación entre los bienes que se salvan y los que se sacrifican, como la que se hace a propósito de la causa de justificación llamada "estado de necesidad". En el segundo caso, no hay ponderación alguna entre bienes, pues no se sacrifica uno como medio para salvar al otro, y por eso es que para realizar el procedimiento basta con que exista una razón suficiente. Un ejemplo de esto último es la administración de analgésicos a un enfermo terminal, aunque estas sustancias puedan tener también el efecto de acortar un poco la vida del paciente.

\footnotetext{
${ }^{1}$ Licenciado en Ciencias Jurídicas Pontificia Universidad Católica de Chile, Abogado, Profesor de Magíster en Criminología, Universidad Central, Profesor de Derecho Penal, Universidad Diego Portales, Correo Electrónico: jhermosilla@hermosilla.cl

${ }^{2}$ Licenciado en Ciencias Jurídicas Pontificia Universidad Católica de Chile, Doctor en Derecho por la Universidad de Bonn, Profesor Derecho Penal Económico, Pontificia Universidad Católica de Chile, Correo Electrónico: avanweezel@claro.cl.
} 


\section{2) ¿CONSIDERA USTED QUE ES NECESARIO INTRODUCIR MODIFICACIONES LEGISLATIVAS RESPECTO DE LA POSIBILIDAD DE INTERRUMPIR UN EMBARAZO DE ALTO RIESGO HOY EN CHILE? ¿QUÉ OPONIÓN LE MERECE LA IDEA DE QUE ESA FIGURA ESTÁ CUBIERTA POR LA LEX ARTIS Y POR EL CUMPLIMIENTO DEL DEBER PROFESIONAL DEL MÉDICO?}

JPH: Creo que para no penalizar las hipótesis de aborto terapéutico no es necesario modificar la ley, pero podría ser bueno reponer el texto original del artículo 119 del Código Sanitario para evitar dudas al respecto. En mi opinión, el médico que realiza una acción destinada a proteger la salud y la vida de la madre, que implica la muerte del feto, no realiza una acción matadora propia del tipo del aborto, sino que una acción sanadora conforme a la Lex Artis, adecuada a derecho y amparada en el artículo 10 No 7 del Código Penal (estado de necesidad). Habitualmente concurrirán hipótesis de inculpabilidad, además, si se pensara en descartar los argumentos precedentes.

AVW: Si por aborto terapéutico se entiende "realizar un procedimiento donde la muerte de la criatura no es el medio para curar, pero puede sobrevenir como consecuencia no deseada", en mi opinión no es necesario modificar para nada la legislación actual, pues el médico que cumple su deber profesional haciendo lo que el estado de la ciencia médica le indica hacer para intentar salvar ambas vidas, crea para la criatura (y para su madre) un riesgo que está permitido por el ordenamiento jurídico. Se trata de una conducta socialmente adecuada, y por lo tanto ya desde un comienzo no comprendida en el tipo penal. Y para quienes no comparten esta visión del delito, la conducta quedará excluida del ámbito del derecho penal, como muy tarde, al examinar si se halla justificada por el ejercicio legítimo de una profesión. Ni siquiera hay una "colisión de deberes", pues cuando el médico realiza todo lo que está de su parte para salvar la vida de la madre y la de la criatura, no está dejando de cumplir un deber para satisfacer otro.
Pero si por aborto terapéutico se entiende "matar a la criatura como medio para lograr un buen fin (curativo)", entonces se requiere mucho más que un cambio legislativo puntual, porque, cualquiera que sea la forma en que se haga, declarar esa acción conforme al ordenamiento jurídico implica declarar que el derecho da a una persona la potestad de decidir sobre la vida y la muerte del que está por nacer, que es posible disponer de la vida de esa criatura matándola, lo cual es algo que el ordenamiento jurídico chileno siempre ha prohibido, aunque el Derecho muchas veces suspenda el juicio de reproche a la persona que actuó en situación de angustia y presión psíquica o incluso física.

Aquí se suele producir una confusión debido al denominado "finalismo" en derecho penal. Como el dolo se extiende también a las "consecuencias seguras" de una conducta, cuando alguien actúa con la intención de alcanzar un objetivo, pero sabe que adicionalmente se producirá otro efecto, también tendría dolo respecto de este efecto (en este caso, respecto de la muerte del nasciturus). Pero en este razonamiento falta una pieza fundamental: la categoría penal del dolo solo tiene sentido cuando se refiere a un hecho que objetivamente es una perturbación social relevante para el derecho penal, por lo cual lo primero no es saber si alguien actuó o no con dolo, sino si creó un riesgo prohibido por el derecho. $\mathrm{Y}$ el riesgo de muerte de la criatura en casos de interrupción del embarazo no está prohibido por el derecho penal, en la medida que exista indicación médica de realizarla, conforme a la Lex Artis.

\section{3) ¿QUÉ OPINIÓN LE MERECEN LOS PROYECTOS DE LEY PRESENTADOS EN ESTA MATERIA? ¿CREE USTED QUE ABARCAN A OTROS TIPOS DE ABORTO?}

JPH: Creo que se enmarcan dentro de la lógica de asumir que en casos de conflicto entre el interés de la madre y la vida del feto por regla general ceden en beneficio de la protección de la vida humana dependiente (vida del que está por nacer), pero, que excepcionalmente, en determinados casos prima el interés 
de la madre. Se propone un sistema de indicación, al estilo español. Me parece un sistema adecuado para ser aplicado en Chile.

AVW: En los últimos años se han presentado una serie de proyectos de ley relacionados con el aborto. Algunos se refieren a los normas del Código Penal, otros al Código Sanitario, y otros a la posibilidad de reformar la Constitución. Hay algunos proyectos que tienden a establecer causas de atipicidad o de justificación para lo que ellos mismos llaman "aborto terapéutico", y otros que buscan ampliar la punibilidad de las maniobras abortivas.

Lo más importante es tener presente que cuando la ley declara lícito el aborto que se realiza por ciertos motivos -como preservar mejor la salud de la madre-, lo que se dice es que el aborto por "buenas razones" es un hecho legítimo, acorde con el ordenamiento jurídico vigente. La posibilidad de abortar es una alternativa válida, un curso de acción elegible entre otros que la persona tiene a su disposición.

Pues bien, en el ámbito de la medicina, que se caracteriza por la escasez de recursos, las posibilidades de que la madre sufra un "grave deterioro de su salud" (como señala por ejemplo el proyecto del Boletín No 4845-11) dependen de muchos factores, entre los cuales ocupan un lugar principal las posibilidades reales de otorgar una asistencia médica compleja. En un sistema de salud donde dichas posibilidades reales son pocas y precarias, el aborto es la solución más sencilla y barata. Y nada impedirá que se adopte efectivamente. Por el contrario, si la posibilidad de abortar es una alternativa entre otras, elegible porque la ley la pone a disposición, entonces la opción por una alternativa distinta -más cara y riesgosa- será incluso un acto de irresponsabilidad de la madre y los médicos. ¿No debería soportar la madre sola, sin ayuda del Estado, las consecuencias de haber elegido tener un hijo enfermo, o de enfermarse ella al tenerlo?, ¿por qué tendría que asumir toda la sociedad los costos si ella, pudiendo haber abortado, no lo hizo? Y los médicos: si deciden no realizar el aborto porque pretenden salvar a la madre y a la criatura, pero resulta que aquella fallece, ¿cómo no van a ser responsables de la muerte si pudieron perfectamente haber abortado a la criatura desde un comienzo y no lo hicieron?, ¿por qué no van a tener que responder por las consecuencias previsibles del riesgo que decidieron correr (y que a posteriori siempre será "inmenso") sin que ello fuera necesario?

En una sociedad como la nuestra, que ya no es puramente individualista, la permisión del aborto termina por convertirse en un "deber de abortar".

\section{4) ¿ESTIMA USTED QUE ES COMPATIBLE CON LA CONSTITUCIÓN DE 1980 LA PRETENSIÓN DE LEGALIZAR ALGÚN TIPO DE ABORTO EN CHILE?}

JPH: El sistema de indicación descrito en la pregunta anterior se acomoda a las disposiciones de la Constitución vigente en nuestro país. Es más discutible si ocurre lo mismo con un sistema de plazo, que autorice a la madre a terminar el embarazo con la muerte del feto dentro de cierto plazo (normalmente alrededor de las 12 semanas de embarazo) y cumpliendo con algunos otros requisitos menores. Me inclino a pensar que también podría optarse por un sistema como este sin modificar la Constitución, quedando vedados solo los sistemas de autorizaciones generales a la madre para abortar en cualquier tiempo y forma.

AVW: En ninguna sociedad, tampoco en Chile, existe o puede existir un aborto lícito de personas. Esto se debe a que la persona nunca puede ser objeto de una ponderación. Por eso, para legitimar el aborto "para un buen fin" no sirve el estado de necesidad del art. 10 $N^{\circ} 7 \mathrm{CP}$, sino que es necesario sostener previamente que la criatura en el vientre materno no es una persona de cara al derecho, sino algo distinto. Y como en esta cuestión específica el derecho conoce sólo dos posibilidades -o se es sujeto de derechos, o se es objeto de ellos-, para legitimar el aborto primero hay que declarar que la criatura en el vientre materno es una cosa, un objeto de derechos. En esto consiste una ley que legitima la práctica del aborto, con el fin que sea, y por eso es que muchos 
de sus partidarios -coherentemente- sostienen que el embrión o el feto no es persona, jurídicamente hablando.

Pero ocurre que las ciencias empíricas y la filosofía enseñan que el individuo en el vientre materno es un individuo de la especie humana, no de otra especie distinta, y que su desarrollo desde la concepción es un continuo. Esto significa, entonces, que "despersonalizar" a la criatura significa que alguien -en este caso, el legislador- se arroga la facultad de decidir a cuáles individuos de la especie humana se les reconocerá el estatus persona y a cuáles no.

Para legitimar el aborto en Chile se requeriría una subversión de los bienes y valores sobre los que descansan la sociedad y su ordenamiento jurídico, que siempre han considerado a la criatura aún no nacida como un sujeto y no como un objeto de derechos. 